DR. JOANA CARVALHO (Orcid ID : 0000-0002-4235-1242)

Article type : Primary Research Articles

\title{
A global risk assessment of primates under climate and land use/cover scenarios
}

Running title: Global change-related risks for primates

\section{Authors}

Joana S. Carvalho ${ }^{* 1}$, Bruce Graham ${ }^{1}$, Hugo Rebelo ${ }^{2,3}$, Gaëlle Bocksberger ${ }^{4}$, Christoph F. J. Meyer $^{5}$, Serge Wich ${ }^{6,7} \&$ Hjalmar S. Kühl ${ }^{4,8}$

${ }^{1}$ Faculty of Computing Science and Mathematics, University of Stirling, Stirling, United Kingdom

${ }^{2}$ CIBIO/InBIO, Research Center in Biodiversity and Genetic Resources, University of Porto, Vairão, Portugal

${ }^{3}$ School of Biological Sciences, University of Bristol, Bristol, United Kingdom

${ }^{4}$ Max Planck Institute for Evolutionary Anthropology, Leipzig, Germany

${ }^{5}$ School of Environment and Life Sciences, University of Salford, Salford, United Kingdom

${ }^{6}$ Faculty of Science, Liverpool John Moores University, Liverpool, United Kingdom

${ }^{7}$ Institute for Biodiversity and Ecosystem Dynamics, Universiteit van Amsterdam, Amsterdam, The Netherlands

${ }^{8}$ German Centre for Integrative Biodiversity Research (iDiv), Halle-Leipzig-Jena, Leipzig, Germany

This article has been accepted for publication and undergone full peer review but has not been through the copyediting, typesetting, pagination and proofreading process, which may lead to differences between this version and the Version of Record. Please cite this article as doi: $10.1111 /$ gcb.14671

This article is protected by copyright. All rights reserved. 
*corresponding author: joana.coleoptera@gmail.com

\title{
Keywords
}

Climate change, exposure, extinction risk, hazard, land use/cover change, primate conservation, primate hotspots, species ranges

\begin{abstract}
Primates are facing an impending extinction crisis, driven by extensive habitat loss, land use change, and hunting. Climate change is an additional threat, which alone or in combination with other drivers, may severely impact those taxa unable to track suitable environmental conditions. Here, we investigate the extent of climate and land use/cover (LUC) changerelated risks for primates. We employed an analytical approach to objectively select a subset of climate scenarios, for which we then calculated changes in climatic and LUC conditions for 2050 across primate ranges $(\mathrm{N}=426$ species $)$ under a best- and a worst-case scenario. Generalised linear models were used to examine whether these changes varied according to region, conservation status, range extent, and dominant habitat. Finally, we reclassified primate ranges based on different magnitudes of maximum temperature change, and quantified the proportion of ranges overall and of primate hotspots in particular that are likely to be exposed to extreme temperature increases. We found that, under the worst-case scenario, $74 \%$ of Neotropical forest-dwelling primates are likely to be exposed to maximum temperature increases up to $7^{\circ} \mathrm{C}$. In contrast, $38 \%$ of Malagasy savanna primates will experience less pronounced warming of up to $3.5^{\circ} \mathrm{C}$. About one quarter of Asian and African primates will face up to 50\% crop expansion within their range. Primary land (undisturbed habitat) is expected to disappear across species' ranges, whereas secondary land (disturbed habitat) will increase by up to $98 \%$. With $86 \%$ of primate ranges likely to be exposed to
\end{abstract}

This article is protected by copyright. All rights reserved. 
maximum temperature increases $>3^{\circ} \mathrm{C}$, primate hotspots in the Neotropics are expected to be particularly vulnerable. Our study highlights the fundamental exposure risk of a large percentage of primate ranges to predicted climate and LUC changes. Importantly, our findings underscore the urgency with which climate change mitigation measures need to be implemented to avert primate extinctions on an unprecedented scale.

\section{INTRODUCTION}

Global biodiversity is under serious assault due to a host of anthropogenic activities and climate change (Schloss, Nuñez, \& Lawler, 2012; Thomas et al., 2004). Climate change could exacerbate the effects of the expected drastic alterations in land use during and beyond the $21^{\text {st }}$ century (McClean et al., 2005). In combination, climate and land use/cover (LUC) changes will have negative consequences for many wildlife species, likely driving the extinction of many in the future (Gouveia et al., 2016; Struebig et al., 2015). Thus, when trying to better understand variation in climate-related risks between taxa it is fundamental to consider both the single effects and the synergistic interactions between climate and LUC changes, especially because jointly these global change drivers will pose many challenges to species conservation in the future (Gouveia et al., 2016; Titeux et al., 2017).

Studies assessing climate change impacts on biodiversity are geographically biased towards temperate regions, whereas biodiverse tropical and subtropical regions remain understudied (Pacifici et al., 2015). Although less pronounced changes in climate in the tropics than in temperate regions have been forecast, many tropical species have already exceeded their physiological tolerance limits to changing climatic conditions (Schloss et al., 2012), highlighting that more research on tropical species is particularly urgent (Pacifici et al., 2015; Tewksbury, Huey, \& Deutsch, 2008).

This article is protected by copyright. All rights reserved. 
In addition to being charismatic animals, non-human primates (primates hereafter) are considered flagship species in tropical forest ecosystems whose conservation importance cannot be overstressed. Human activities have already taken a severe toll on primate populations, which are dwindling rapidly, as reflected in their alarming status on the IUCN Red List (Estrada et al., 2017). This is despite the fact that some primates show a certain behavioural flexibility enabling them to adapt and survive in human-modified habitats (Estrada et al., 2017; Estrada, Raboy, \& Oliveira, 2012; Spehar et al., 2018). Several threats including hunting, habitat loss, infectious disease epidemics, large-scale commercial logging, and industrial agriculture are directly contributing to their decline, while others, such as human population growth and increased per capita demand do so indirectly (Estrada et al., 2017; Lehman, Fleagle, \& Tuttle, 2006). Although all of the aforementioned are important drivers of primate declines, ongoing climate change is a delocalized driver, likely contributing to many of these threats (Gouveia et al., 2016; Graham, Matthews, \& Turner, 2016; Lehmann, Korstjens, \& Dunbar, 2010; Ribeiro, Sales, De Marco, \& Loyola, 2016; Wiederholt \& Post, 2010). Primates occur in four major geographic regions: Neotropics, mainland Africa (hereafter Africa), Madagascar, and Asia, with most species inhabiting tropical moist lowland forests. More than half of all primate species are threatened with extinction, with $62 \%$ classified as threatened and 5\% listed as near threatened (Supporting Information Table S1). Madagascar and Asia are hotspots of primate extinction risk (92\% and $77 \%$ of threatened species, respectively), while a comparatively lower percentage of species in the Neotropics and Africa is threatened (44\% and 41\%, respectively) (Table S1) (Estrada et al., 2017).

Climate change is likely to have been an important factor in shaping the evolutionary history of primates (Jablonski, Whitfort, Roberts-Smith, \& Qinqi, 2000; Spehar et al., 2018), and is a potential threat to primate populations and to the resilience of protected areas across their 
range (Africa (Lehmann et al., 2010), Asia (Struebig et al., 2015), Neotropics (Ribeiro et al., 2016) and Madagascar (Kamilar, 2017)). This is either due to its direct effects on primate physiology, or indirectly through its influence on resource availability (Chapman et al., 2005; Isabirye-Basuta \& Lwanga, 2008; Wiederholt \& Post, 2010). Schloss et al. (2012) assessed the ability of mammals to keep pace with climate change, and found that most mammals in the Amazon will not be able to disperse to suitable climates given the fast pace of forecast changes. Moreover, their study suggested that the predicted magnitudes of climate change might exceed the physiological tolerance limits of many species. Among mammals, primates are likely to be the most vulnerable group as they exhibit a number of traits that make them highly susceptible to climate change, such as slow reproduction, low population densities, dietary requirements, and thermoregulation, which limit their dispersal capacity (Schloss et al., 2012). Accordingly, the Intergovernmental Panel on Climate Change (IPCC) drew attention to primates as the mammalian order with the lowest dispersal speed, underscoring that many species likely face an elevated risk of extinction (IPCC, 2014). Interestingly, a few primate taxa such as baboons occupy very large geographic ranges and show environmental flexibility, which would make them physiologically less vulnerable to climate change (Fuchs, Gilbert, \& Kamilar, 2018). Ecological niche models have suggested considerable primate range reductions rather than range expansion or stability, as well as loss of habitat connectivity under climate change (Brown \& Yoder, 2015; Gouveia et al., 2016; Meyer, Pie, \& Passos, 2014; Struebig et al., 2015). Importantly, loss of habitat and connectivity in combination with climate change may severely impact those taxa unable to track climatically-suitable habitats (Gouveia et al., 2016; Titeux et al., 2017).

Patterns of species co-occurrence in primates have been linked to biogeographic history, interspecific competition, predation, and anthropogenic disturbance (Bello et al., 2015; Jablonski et al., 2000; Kamilar, 2017; Spehar et al., 2018). Climate change could be an 
additional factor shaping sympatric species diversity of primates in the future (Graham et al., 2016; Pacifici, Visconti, \& Rondinini, 2018), particularly by altering the structure and composition of their habitats (Isabirye-Basuta \& Lwanga, 2008; Jablonski et al., 2000). Understanding how climate change is likely to affect primate hotspots, i.e. areas with highest species richness, is relevant to ensure effective conservation efforts, however, such assessments are currently lacking.

Most assessments of future climate change-related risks, LUC change, or their combined effects for primates to date were regional-scale analyses (Brown \& Yoder, 2015; Gouveia et al., 2016; Meyer et al., 2014; Ribeiro et al., 2016), relied on earlier, now outdated IPCC climate emission scenarios (Brown \& Yoder, 2015; Graham et al., 2016; Meyer et al., 2014), or did not consider mechanistically relevant variables representing seasonal variations or extreme climate change (Graham et al., 2016; Lehmann et al., 2010; Pacifici et al., 2018). Consequently, in this study we expanded on this earlier work and for the first time quantified climate-related risks of all 426 primate species currently available in the IUCN database (IUCN, 2018) to changing climatic and LUC conditions predicted for the year 2050. We modelled variation in hazard (magnitude of projected climate and LUC change) and exposure (likelihood to experience the hazard) risks (IPCC, 2014; Pacifici et al., 2018) in relation to geographic region, conservation status, range extent, and predominant habitat, and quantified the percentage of species ranges and primate hotspots likely to be exposed to extreme climate changes. Specifically, we addressed the following questions: (1) Which regions are likely to be most affected by altered temperature, precipitation and LUC conditions? (2) Will species listed as threatened face greater risks to both global drivers than non-threatened species? (3) Are small-range species more exposed to climate-related risks? (4) Will the synergistic effects between climate change and habitat loss affect forest and savanna primates differently? (5) What proportion of species ranges will be exposed to extreme maximum 
temperature increases? and (6) What proportion of primate hotspots will be affected by extreme warming?

\section{MATERIALS AND METHODS}

\section{Primate data}

Data on primate geographic ranges were compiled from the IUCN Red List of Threatened Species database (IUCN, 2018). This database contains 426 primate species from 74 genera and 16 families (Table S1), and also provides information about conservation status (critically endangered (CR), endangered (EN), vulnerable (VU), near threatened (NT), least concern (LC) and data deficient (DD)) and range extent $\left(\mathrm{km}^{2}\right)$. In addition, for each primate species, we collated information on geographic region (Lehman et al., 2006), and predominant habitat in its range. The latter was extracted from the land cover data provided by the MODIS-based global land cover climatology dataset (Broxton et al., 2014). This dataset integrates global land cover information from 10 years (2001-2010, at 500 m resolution) and features 16 global land cover classes based on a supervised decision-tree algorithm. We reclassified these into three land cover types: forest, savanna, and other (includes shrubland, grassland, wetland, cropland, urban areas and snow), and extracted the average of each habitat type (in $\mathrm{km}^{2}$ ). Forest and savanna represent the most suitable habitats for primates (IUCN, 2018).

All spatial data were standardized to a resolution of 2.5 arc-minutes $(\sim 4.5 \mathrm{~km}$ at the equator line) and projected into WGS84 Mercator geographic coordinate system. All analyses were performed using the software ArcGIS (ESRI, 2011) and R (R Development Core Team, 2018).

This article is protected by copyright. All rights reserved. 


\section{Climatic variables and climate emission scenarios}

Bioclimatic variables (hereafter climatic variables) based on temperature and precipitation for current and future conditions were compiled from WorldClim (periods of 1950-2000 and 2050, respectively; version 1.4, available at www.worldclim.org; for more details see (Hijmans, Cameron, Parra, Jones, \& Jarvis, 2005)). All climatic variables ( $\mathrm{N}=19)$ representing current conditions were extracted for each primate species' range. As adopted by the IPCC for its Fifth Assessment Report (IPCC, 2014), a new set of global climate change scenarios resulting from a combination of general circulation models (GCMs) with mitigation policies regarding greenhouse gas emission scenarios (Representative Concentration Pathways, RCPs $\left(\mathrm{W} / \mathrm{m}^{2}\right)$ ) were compiled for 2050 (Table S2). RCPs explore alternative technology and land use patterns, as well as socio-economic and climate policy (Moss et al., 2010; IPCC, 2014). These emission scenarios are based on natural and humandriven impacts on future radiative forcings, i.e. changes in the balance of incoming and outgoing radiation to the atmosphere caused by changes in atmospheric components such as carbon dioxide, methane and nitrous oxide (Moss et al., 2010), to describe four different $21^{\text {st }}$ century pathways of greenhouse emissions: RCP 2.6, RCP 4.5, RCP 6.0 and RCP 8.5. RCP 2.6 represents a stringent mitigation scenario, $\mathrm{RCP} 4.5$ and 6.0 are intermediate mitigation scenarios, and RCP 8.5 is a low mitigation scenario with very high greenhouse emissions. The IPCC recommends the use of a large ensemble of climate scenarios produced from combinations of 19 GCMs and 4 RCPs, however, many studies to date relied on climate scenarios that were arbitrarily chosen (Baker et al., 2015; Garden, O’Donnell, \& Catterall, 2015; Thuiller, 2004). Moreover, the magnitude of projected climate change is substantially affected by the choice of emission scenario by mid- $21^{\text {st }}$ century (IPCC, 2014). Thus, we used k-means clustering (Casajus et al., 2016) to objectively select a subset of climate emission scenarios. This method decreases the number of climate scenarios to evaluate while retaining

This article is protected by copyright. All rights reserved. 
the central tendencies and coverage of uncertainty in future climatic conditions. Additionally, it improves the representativeness of climate scenarios at the regional scale by avoiding the common misrepresentation of climate scenarios resulting from an arbitrary selection (Casajus et al., 2016). All GCMs $(\mathrm{N}=19)$ for RCPs 4.5, 6.0, and 8.5 were considered and extracted for each primate species' range. We excluded RCP 2.6 because trends in greenhouse emissions predicted by the other RCPs better represent actual emissions since 2000 (Peters et al., 2011).

\section{LUC data and future scenarios}

Global LUC data for current conditions and 2050 projections were compiled from the Land Use Harmonization Project (period of 1500-2100, at 50 km resolution) (Chini, Hurtt, \& Frolking, 2014; Hurtt et al., 2011), which smoothly combines LUC history data with future scenario information from multiple GCMs into a consistent gridded set of LUC scenarios. Project outputs informed the IPCC Fifth Assessment Report and LUC scenarios are the same used to derive the climate scenarios. GCMs are combined with RCPs: IMAGE 2.6, MiniCam 4.5, AIM 6.0, and MESSAGE 8.5. The very low stabilization scenario IMAGE 2.6 predicts rapid conversion of primary vegetation, especially in the tropics, to crops and biofuels. In contrast, MiniCam 4.5 predicts decrease in both cropland and pasture areas as a result of reforestation programs, crop yield improvements and dietary shifts (Hurtt et al., 2011; Newbold et al., 2015). A decrease in pasture areas as a consequence of more intensive husbandry and increase in cropland due to increasing food demand are predicted by AIM 6.0. Widespread expansion of croplands and pasture areas due to increasing global human population is expected in the high-emission pathway MESSAGE 8.5. All scenarios project an increase in wood harvesting, contributing to large increases in secondary land and, consequently, to large reductions in primary land. For more detailed information on these

This article is protected by copyright. All rights reserved. 
scenarios see Hurtt et al. (2011) and Chini et al. (2014). Of the five available land use states we selected for this study those that best represent biomes where most primates occur: primary land, secondary land, and cropland. Primary land refers to the natural vegetation (either forest or non-forest) undisturbed by humans, and secondary land corresponds also to natural vegetation previously disturbed by human activities (e.g. agriculture or wood harvesting), but recovering, both since the simulation start year of 1500. Thus, primary land and cropland represent the most and least suitable habitat for primates, respectively, with secondary land occupying an intermediate position.

\section{Climate and LUC change-related risks for primates and their correlates}

All climate $(\mathrm{N}=19)$ and LUC variables $(\mathrm{N}=3)$ for the current conditions were assessed for collinearity by conducting a spatial principal component analysis (PCA) (R package 'stats'). The variable with the strongest correlation for the first five principal components was selected. Only 30 future climate scenarios were available for the five climatic variables selected by the PCA (Table S2), and tested with the k-means clustering approach (Casajus et al., 2016).

Mean changes in climatic and LUC variables across each species' range between 2050 and present were calculated. For that, only climatic variables selected in the PCA were considered as well as each climate change scenario selected by the k-means clustering approach.

To examine whether risks to changes in climatic and LUC conditions vary according to region (Neotropics, Africa, Madagascar and Asia), conservation status (CR, EN, VU, NT, LC, DD), range extent $\left(<10 \times 10^{3} \mathrm{~km}^{2},>10 \times 10^{3}\right.$ and $<50 \times 10^{3},>50 \times 10^{3}$ and $<25 \times 10^{4},>25 \times 10^{4}$ and $<10 \times 10^{5},>10 \times 10^{5}$ and $<40 \times 10^{5}$, and $>40 \times 10^{5}$ ) and predominant habitat (forest, savanna, and other), we performed generalised linear models using R package 'glmulti' (Calcagno, 2013). This package is optimized to deal with large candidate model sets and provides a

This article is protected by copyright. All rights reserved. 
flexible way to carry out automated information-theoretic model selection and multi-model inference (Calcagno \& de Mazancourt, 2010). A Gaussian distribution with an identity link function was used, specifying interactions between all variables. Non-normally distributed residuals for the climatic variables were corrected using a log-transformation in the models, but untransformed values were used when plotted. For each response variable, a confidence set of candidate models was selected based on the Akaike Information Criterion $\left(\Delta \mathrm{AIC}_{\mathrm{c}}<2\right)$, and the corresponding model-averaged regression coefficients and Akaike weights were calculated. For each significant effect in the best model for each response variable, the corresponding percentage of species affected was calculated.

\section{Exposure risk of ranges and primate hotspots to extreme warming}

Understanding of climate change-related risks is hampered by a lack of knowledge about the precise magnitudes of change, however, it is accepted that risks will increase with rising temperature (IPCC, 2014). According to the IPCC, moderate risks associated with extreme climate change are expected with increases in global mean temperature of $1-2^{\circ} \mathrm{C}$ above preindustrial levels, and high to very high risks with temperature rises $4^{\circ} \mathrm{C}$ or above. To represent different levels of risk associated with climate change, we considered four magnitudes of change in maximum temperature of the warmest month $\left(\mathrm{T}_{\max }\right)\left(<2^{\circ} \mathrm{C},>2^{\circ} \mathrm{C}\right.$, $>3^{\circ} \mathrm{C}$, and $>4^{\circ} \mathrm{C}$ ) under a worst-case scenario (RCP 8.5 ) to quantify the cumulative percentage of each species' range (total and by family) likely to be exposed to these magnitudes by 2050 and, for each species' range, the number of sympatric primate species. For that, a spatial layer representing changes in $\mathrm{T}_{\max }$ across primate ranges was reclassified into the aforementioned four magnitudes of change and then superimposed on the primate ranges to extract the number of pixels within each species' range that corresponded to each category. We further identified those primate species likely to have more than $50 \%$ of their

This article is protected by copyright. All rights reserved. 
range exposed to extreme $\left(>4^{\circ} \mathrm{C}\right)$ increases in $\mathrm{T}_{\max }$. Finally, the number of sympatric species was grouped into four classes (1-5, 6-10, 11-15, and 16-19) and for each magnitude of change in $\mathrm{T}_{\max }$ we quantified the percentage of overlapping range.

Previous studies have advocated greater consideration of variation or extremes in climatic conditions when modelling the impacts of climate change on primate distribution (Fuchs et al., 2018; Graham et al., 2016; Ribeiro et al., 2016). We therefore considered $\mathrm{T}_{\max }$ as the most suitable proxy variable for assessing climate-change risk, given that high to very high risks are expected with temperature rises $4^{\circ} \mathrm{C}$ or above (IPCC, 2014), and the same magnitude of change was found for minimum temperature of the coldest month $\left(\mathrm{T}_{\min }\right)$ and no relevant changes were observed for precipitation of the wettest month $\left(\mathrm{P}_{\text {wet }}\right)$ (see Results). Only a worst-case scenario was considered for these analyses because our main interest here was to inform upstream planning (Lehmann et al., 2010; Ribeiro et al., 2016) and most countries where primates occur are suffering from high levels of corruption and weak governance and, consequently, low mitigation policies regarding climate change (Estrada et al., 2018; IPCC, 2014, 2018).

\section{RESULTS}

\section{Selection of variables and future scenarios}

The PCA captured $84 \%$ of the total variance in the first five principal components, which were most strongly correlated with the following variables: $T_{\min }(-0.32, \mathrm{PC} 1: 40.6 \%$ of variance), $T_{\max }(-0.38, \mathrm{PC} 2: 19.7 \%), P_{\text {wet }}(0.52, \mathrm{PC} 3: 12.5 \%)$, secondary land (-0.59, PC4: 6.0 $\%)$, and cropland and primary land (-0.56 and 0.56, respectively, PC5: 5.6\%) (Table S3). Reduction of 30 climate emission scenarios via k-means clustering resulted in six clusters summarizing $86 \%$ of the variance and with sizes between one and six climate scenarios (Table S4, Fig. S1). To simplify the interpretation of the results, and given that some 
scenarios forecast the same magnitude of change (Fig. S2), below we only contrast predicted outcomes under the best-case scenario (i.e. high mitigation scenario) and the worst-case scenario (i.e. low mitigation scenario) in modelling changes in climatic conditions (CCSM4 4.5 (hereafter CC 4.5) and HadGEM-ES 8.5 (hereafter HE 8.5), respectively) and in land use/cover conditions (MiniCam 4.5 and MESSAGE 8.5, respectively) for the year 2050 (Fig. $\mathrm{S} 1, \mathrm{~S} 2)$.

\section{Climate change-related exposure risk of primate ranges}

For $\mathrm{T}_{\max }$ and $\mathrm{T}_{\min }$, under both scenarios, model selection provided overriding support $\left(\mathrm{w}_{\mathrm{i}}=\right.$ 0.76-0.96) for region, conservation status, habitat and range size influencing risk exposure. For $\mathrm{P}_{\mathrm{wet}}$, region and habitat were identified as key predictors under both scenarios, however, there was some model selection uncertainty, especially for the best-case scenario (Table S5, S6).

Primate species will face an increase in $\mathrm{T}_{\max }$ and $\mathrm{T}_{\min }$ throughout their range of distribution under both scenarios (Fig. 1a,b; Fig. S3). In the Neotropics, an increase of $>2^{\circ} \mathrm{C}$ in $\mathrm{T}_{\max }$ is likely, with particularly dramatic increases of up to $7^{\circ} \mathrm{C}$ expected for Central and Northern Brazil under the worst-case scenario. Forest primates will be the most affected by these changes (74\% of all Neotropical species) (Fig. S3; Table 1, S1). An increase in $\mathrm{T}_{\max }$ of up to $5^{\circ} \mathrm{C}$ is predicted for southern Africa (23\% of all species), as well as for North-East and SouthEast Asia (23\% of all species) under the worst-case scenario (up to $3^{\circ} \mathrm{C}$ in the best-case scenario). In contrast, under both scenarios, changes are likely less pronounced in Madagascar (up to $3.5^{\circ} \mathrm{C}$ ), particularly for savanna primates (38\% of all Malagasy species). Both scenarios also project that primate species with larger ranges are likely to face an increase in $\mathrm{T}_{\max }$. Exposure risk did not vary significantly among species depending on their conservation status under the worst-case scenario while those currently listed as LC (29\% of

This article is protected by copyright. All rights reserved. 
all species) might experience an elevated risk under the best-case scenario (Fig. S3; Table 1, S1).

According to the worst-case scenario, $\mathrm{T}_{\min }$ is forecast to increase up to $5^{\circ} \mathrm{C}$ (up to $3^{\circ} \mathrm{C}$ in the best-case scenario) in all major primate regions, particularly in Central Brazil and Africa, and China (here affecting mostly primates living in less forested habitats, i.e. $18 \%$ of all Asian species) (Fig. 1a,b; Fig. S3; Table 1, S1). In contrast, the ranges of Neotropical savanna primates will experience less marked increases of up to $2.5 / 4^{\circ} \mathrm{C}$ (best-/worst-case scenario; $20 \%$ of all Neotropical species). Again, Madagascar is likely to face only small increases up to $3^{\circ} \mathrm{C}$ under the worst-case scenario (up to $1.5^{\circ} \mathrm{C}$ in the best-case scenario), affecting $51 \%$ of non-forest Malagasy primates. Changes in $\mathrm{T}_{\min }$ will differentially affect species depending on conservation status, and will influence primates with larger ranges more (Fig. S3; Table 1). The best-case scenario predicts an increase up to $100 \mathrm{~mm}$ in $\mathrm{P}_{\text {wet }}$ across the ranges of Asian and Malagasy primates in less forested habitats (18\% and 51\% of species, respectively) (Fig. 1a, S3; Table 1, S1). In contrast, decreases up to $-200 \mathrm{~mm}$ are forecast for the same primate ranges under the worst-case scenario (Fig. 1b). Decreases in $\mathrm{P}_{\text {wet }}$ are likely across most primate ranges in the Neotropics (up to $-100 \mathrm{~mm}$ ), and in some coastal countries in West and southern Africa (up to -150 mm) under both scenarios (Fig. 1a,b; Fig. S3; Table 1, S1). No significant differences in exposure risk with regard to $\mathrm{P}_{\text {wet }}$ were found for species conservation status or range extent (Table 1).

\section{LUC change-related exposure risk of primate ranges}

Region and habitat were key correlates of predicted changes in cropland, secondary, and primary land, being included in all best-supported GLMs (Table S5, S6). Most species' ranges are expected to face crop expansion under both scenarios, particularly in West and East Africa (23\% of total species) and in most of Asia (21\% of non-forest Asian species)

This article is protected by copyright. All rights reserved. 
where large increases in cropland of up to $50 \%$ are likely, and in the South-Eastern Neotropics (31\% of total species) with projected increases up to $25 \%$ (Fig. 2a,b; Fig. S3;

Table 1, S1). Only up to $7 \%$ crop expansion is expected for Malagasy primate ranges (13\% of Malagasy species living in less forested habitats) under the best-case scenario, and up to $25 \%$ under the worst-case scenario. Interestingly, under the best-case scenario primate ranges in Central Africa and in the North-Eastern Neotropics might see a substantial reduction of up to $50 \%$ in cropland area, in contrast with the forecast increases up to $25 \%$ under the worst-case scenario (Fig. 2a,b; Fig. S3).

Increases in secondary land are likely to occur in all primate habitats across all regions (up to $90 \%$ and $60 \%$ under the best-case and worst-case scenarios, respectively), with the exception of Madagascar which could face losses up to $60 \%$ (affecting $51 \%$ of Malagasy species living in less forested habitats) under the worst-case scenario, and West and North Africa with up to $40 \%$ reduction (23\% of total species) under both scenarios (Fig. 2a,b; Fig. S3; Table 1, S1). In contrast, primary land is bound to disappear in most primate ranges, regardless of the scenario (Fig 2a,b). In this respect, most of the Neotropics (up to 98\%; affecting most Neotropical non-forest primates, i.e. $26 \%$ of all Neotropical species), Africa (up to 95\%; African forest primates, i.e. $50 \%$ of all African species), and Northern Asia (up to 90\%; Asian non-forest primates, i.e. 19\% of all Asian species) will suffer the most pronounced changes. Exposure risk to LUC changes was unrelated to range extent, even though primates with larger ranges will be experiencing only mild reductions in primary land compared to those with smaller ranges (Fig. S3, Table1).

\section{Exposure risk of ranges and primate hotspots to extreme warming}

Under the worst-case scenario, increases $>2^{\circ} \mathrm{C}$ in $\mathrm{T}_{\max }$ are predicted to affect primates throughout nearly $100 \%$ of their ranges (Fig. 3, S4). Large fractions of the ranges of

This article is protected by copyright. All rights reserved. 
Neotropical (86\%) and African (61\%) primates are likely to be exposed to $>3^{\circ} \mathrm{C}$ warming, while changes of this magnitude will only affect $36 \%$ and $25 \%$ of the ranges of Asian and Malagasy primates, respectively (Fig. 3). At the family level, Cebidae and Atelidae in the Neotropics (up to $25 \%$ of range) as well as Cercopithecidae in Africa and Asia (up to $38 \%$ and $30 \%$ of range, respectively) will be those most affected by increases in $\mathrm{T}_{\max }$ of this magnitude. Extreme $\left(>4^{\circ} \mathrm{C}\right) \mathrm{T}_{\max }$ increases are forecast for almost half $(41 \%)$ of Neotropical primate ranges, in contrast to only $5 \%$ for Africa and Asia. Malagasy primates are unlikely to experience such extreme warming (Fig. 3). Again, ranges of the families Cebidae and Atelidae are likely to be the most affected (up to 12\%) by such extreme changes. Of the 42 species likely to experience an extreme increase in $\mathrm{T}_{\max }\left(>4^{\circ} \mathrm{C}\right)$ in more than $50 \%$ of their range 25 are currently listed as non-threatened, however, a considerable fraction $(\mathrm{N}=15)$ is already threatened and two are classified as DD (Fig. S4, Table 2). The dominant habitat of these species is forest $(\mathrm{N}=35)$, followed by savanna $(\mathrm{N}=6)$ and other habitats $(\mathrm{N}=1)$, and nearly all of them are Neotropical species $(\mathrm{N}=38$; Asia: $\mathrm{N}=3$, Africa: $\mathrm{N}=1)$. Eight Neotropical species are likely to have their entire range exposed to $\mathrm{T}_{\max }$ extremes (Alouatta discolour, Ateles marginatus, Callicebus baptista, C. moloch, Mico emiliae, M. humeralifer, M. leucippe, Saguinus martinsi), as opposed to only one Asian species, Trachypithecus laotum (Fig. S4, Table 2).

With up to 19 sympatric primate species, Africa is the world's prime hotspot in terms of primate richness, followed by Madagascar and the Neotropics with up to 15 sympatric species, whereas Asian primate assemblages do not exceed 10 species (Fig. 4). For Africa, those areas where the most primate hotspots occur represent $59 \%$ and $34 \%$ of primate ranges that are likely to be exposed to increases in $\mathrm{T}_{\max }>2^{\circ} \mathrm{C}$ and $>3{ }^{\circ} \mathrm{C}$, respectively, under the worst-case scenario. For Madagascar, the equivalent figures are $40 \%$ and $14 \%$, respectively. Primate hotspots for Asia correspond to $29 \%$ and $5 \%$ of the ranges likely to be exposed to

This article is protected by copyright. All rights reserved. 
$\mathrm{T}_{\max }>3^{\circ} \mathrm{C}$ and $>4^{\circ} \mathrm{C}$, respectively. In contrast, primate hotspots in the Neotropics will be most imperilled, with $53 \%$ of ranges likely to be exposed to $\mathrm{T}_{\max }$ increases $>3^{\circ} \mathrm{C}$ and $19 \%$ to extreme warming $\left(>4^{\circ} \mathrm{C}\right)$.

\section{DISCUSSION}

Although we have presented results both for a high (RCP 4.5) and a low mitigation scenario (RCP 8.5), the latter probably represents the actual situation in most primate regions more accurately due to the weak mitigation policies in place in these countries (IPCC, 2014, 2018; Peters et al., 2011). Moreover, no climate-related mitigation measures have been proposed specifically for primates yet (Korstjens \& Hillyer, 2016). To best inform upstream planning, the results are thus discussed primarily under the assumption of a worst-case scenario as the more likely outcome. Our findings suggest that most primate regions will be facing extreme temperature increases, whereby Neotropical forest-dwelling primates will be most affected. In addition, projected decreases in precipitation are likely to affect mostly Asian and Malagasy species that inhabit less forested habitats. Moreover, our analyses indicate that warming will affect species irrespective of threat status and those with larger ranges will be more exposed to anticipated temperature changes, whereas such a pattern was not evident for precipitation. We further found that crop expansion is predicted to invade the majority of primate ranges, particularly in Africa, Asia and the Neotropics. Large increases in secondary land are expected across all regions, while primary land will largely disappear, particularly where primates are confined to forests and where less threatened species are presently found. Neotropical species are likely to be highly exposed to increases in $\mathrm{T}_{\max }>3^{\circ} \mathrm{C}$ in most of their ranges, and several species were identified whose entire range will be exposed to extreme warming $\left(>4^{\circ} \mathrm{C}\right)$. Finally, half of the area of primate hotspots in the Neotropics is predicted to face warmings $>3^{\circ} \mathrm{C}$.

This article is protected by copyright. All rights reserved. 


\section{Climate change-related risks for primate ranges due to extreme warming}

Our analyses revealed that among all major primate regions, Madagascar is likely to be the one that will be least affected by climate change. In contrast, effects are likely to be most pervasive in the Neotropics, exposing especially forest-dwelling primates to highly elevated $\mathrm{T}_{\max }$ across their ranges. Conservation efforts should thus be focused on forest habitats to avert extinctions of Neotropical primates. Many ranges in Africa and Asia are also likely to be affected by climate change, in line with similar broad-scale trends reported by previous studies. For example, Gaffney (2011) suggested that primate ranges in Central America, North-West Africa and South-East Asia will be particularly impacted by climate change. Similarly, Graham et al (2016) found that Central America, the Amazon basin, North and East Africa and East and South-East Asia will be climatically unsuitable for primates in the future. Finally, Ribeiro et al (2016) suggested that species inhabiting the south-western regions of the Neotropics, and particularly Amazonian primates, will probably be unable to keep pace with climate change due to the high velocity of change expected in the tropics and poor dispersal abilities of species (Schloss et al., 2012).

Many species are considered to be at very high risk of extinction if exposed to global mean temperatures over $4^{\circ} \mathrm{C}$ above pre-industrial levels (IPCC, 2014). No studies to date have quantified the thermal limits of primates to global warming, and only few have used thermal indices to assess current climatic data against behavioural data (e.g. Pruetz, 2018; Tagg et al., 2018). Sherwood and Huber (2010) quantified the upper thermal limits in humans through a temperature-humidity index that measures heat stress. They concluded that a global mean warming of about $7^{\circ} \mathrm{C}$ would be intolerable by humans, given that metabolic heat dissipation would become impossible under these extremes. Moreover, even temperature increases of 3$4^{\circ} \mathrm{C}$ are likely to surpass the thermal tolerance and to create limitations to cooling in humans (Sherwood \& Huber, 2010). Despite the well-known behavioural flexibility of primates to

This article is protected by copyright. All rights reserved. 
adapt to novel environmental conditions (Estrada et al., 2017, 2012; Fuchs et al., 2018; Spehar et al., 2018), they have relatively limited dispersal abilities for their body size, slow reproduction, low population densities, dietary requirements, and thermoregulation, and many of them might already have surpassed their thermal tolerance to climate conditions. Even if some species migrate to more suitable areas or adapt in situ, the current human pressure on primate habitats as well as the predicted reduction of up to $86 \%$ of their range with $>3^{\circ} \mathrm{C}$ warming are likely to constrain their dispersal. Thus, we can expect that most, but in particular Neotropical primate species, will be widely exposed to extreme changes in climatic conditions, likely being highly vulnerable to and facing an elevated risk of extinction due to climate change.

\section{LUC change-related risks for primate ranges due to extreme warming}

Recent global food crises have greatly contributed towards the intensification and major expansion of tropical agriculture (Laurance, Sayer, \& Cassman, 2014). Primates will experience future crop expansion throughout most of their ranges, particularly in Africa and Asia where half of primate ranges will be lost due to agricultural expansion (Estrada et al., 2017, 2012; Wich et al., 2014). For the $21^{\text {st }}$ century, Estrada et al (2017) predict that $68 \%$ of the current range of primates will be under agriculture. In general, most primary land is likely to disappear and will be replaced by secondary land in up to $98 \%$ of primate ranges. Despite the ecological and behavioural resilience of some primate species to cope with anthropogenic habitat modification (Estrada et al., 2017, 2012; Fuchs et al., 2018; Spehar et al., 2018), adverse side effects such as hunting, disease transmission, and human-primate conflicts will exacerbate the vulnerability of primates to LUC change and potentially lead to regional extinctions within their current distribution (Estrada et al., 2018; Gaffney, 2011; Struebig et al., 2015). Moreover, greater increases in habitat loss are expected where climate and LUC

This article is protected by copyright. All rights reserved. 
changes act synergistically (Gaffney, 2011; Struebig et al., 2015), amplifying the importance of expanding landscape connectivity among areas of suitable habitats for primates to ensure their conservation.

\section{Risks to primate hotspots due to extreme warming}

Significant losses in terms of primate ranges are likely as a result of anticipated levels of climate change, particularly in the Neotropics and Africa, in line with previous studies (Graham et al., 2016; Pacifici et al., 2015; Ribeiro et al., 2016). Importantly, our study quantified the percentage of range potentially exposed to different magnitudes of $T_{\max }$ change, and $>3^{\circ} \mathrm{C}$ warming is forecast for up to $86 \%$ of Neotropical primate ranges, and extreme warming $\left(>4^{\circ} \mathrm{C}\right)$ for almost half $(41 \%)$ of their ranges. Ribeiro et al (2016) also predicted a risk exposure up to $3.5^{\circ} \mathrm{C}$ in more than $80 \%$ of Amazon primate ranges under a worst-case scenario. Moreover, our study suggests that primate hotspots in the Neotropics will to a considerable extent ( $19 \%$ of ranges) be exposed to extreme warming $\left(>4^{\circ} \mathrm{C}\right)$. Pacifici et al. (2018) identified western Amazonia as well as central and eastern Sub-Saharan Africa as important hotspots of mammals, including primates, that face an elevated risk from climate change. Our study thus suggests that allocating effective conservation efforts across their ranges based on primate hotspots is a key approach to minimizing the potential risk of climate change-driven primate extinctions (Graham et al., 2016).

Climate and LUC changes will alter patterns of plant species composition and productivity (Chapman et al., 2005), therefore likely leading to a reduction in resource availability for primates (Wiederholt \& Post, 2010). This in turn may exacerbate interspecific competition for food (Rocha, Pinto, Boubli, \& Grelle, 2015), compromising the persistence of sympatric species and increasing primate vulnerability to climate change as many taxa will be unable to track climatically-suitable habitats (Titeux et al., 2017). For example, Ateline primates are

This article is protected by copyright. All rights reserved. 
likely to be extremely affected by decreases in resource availability due to extreme climate events (e.g. El Niño) (Wiederholt \& Post, 2010). Climate-related mitigation measures for primates are imperative not only to ensure their survival, but because the negative consequences with respect to ecosystem services provided by these flagship species could be irreversible and other functional interactions could be lost (Bello et al., 2015).

\section{Strategies to mitigate environmental change impacts on primates}

Mitigation, together with adaptation to climate change, is an integrative approach recommended by the IPCC which intends to reduce forecast climate change effects across different temporal and spatial scales (IPCC, 2014, 2018). The most efficient integration of mitigation and adaptation strategies is strictly dependent on policies and cooperation in governance at international, regional, and national scales. Effective conservation actions across primate regions depend on the intrinsic environmental and socio-economic aspects of each country (Estrada et al., 2018). However, lack of law enforcement, weak governance, and economic development locally, and demands for food and forest products globally, will continue to boost pressures on primate populations (Estrada et al., 2018). No climate-related mitigation measures have been proposed specifically for primates yet, however, suggested priority strategies for biodiversity conservation in general which may also be applicable to primates include: forest preservation, restoration, reforestation and afforestation, increasing habitat connectivity, and reintroduction and translocation (Korstjens \& Hillyer, 2016). Because deforestation is a major contributor to climate change, global initiatives for effective and sustainable landscape planning to conserve forests and carbon stocks, e.g. through the United Nations REDD + programme, are considered important to expand and connect forested habitats (Lecina-Diaz et al., 2018). Moreover, agroforests can provide important habitats for primates and small-scale agroforestry can contribute to forest 
conservation and habitat connectivity (Estrada et al., 2012). Finally, translocations and reintroductions of primates need to follow strict guidelines (IUCN, 2012) and should be considered as a last resort.

Importantly, most primates are currently distributed in protected areas rich in natural resources (Estrada et al., 2018). Even in the context of limited funding and under growing land use pressure, some protected areas in the tropics have been effective in protecting biodiversity and ecosystems, promoting connectivity, and making a significant contribution to long-term biodiversity conservation (CBD, 2010). However, one-third of protected areas are under intense human pressure globally (Jones et al., 2018). Given that climate change is likely to intensify levels of mobility in human populations (Tacoli, 2009), invasions of climate refugees into protected areas are likely to occur, consequently posing an additional threat to primates. Future studies assessing the effects of climate refugees on protected areas will be central for devising effective conservation strategies that mitigate detrimental impacts on primates and their habitats.

\section{Study limitations}

Uncertainty in projections of climate scenarios is widely documented (see Sokolov et al., 2009), and considerable efforts have been made to quantify it when predicting anthropogenic global warming either taking into account mitigation policies (IPCC, 2014, 2018) or not (Sokolov et al., 2009). In comparison to past IPCC scenarios, the new set of global climate change scenarios 1) incorporates a substantially larger knowledge base of scientific, technical and socio-economic literature, 2) better characterises the uncertainty in long-term projections, and 3) improves both the simulation of continental-scale surface temperature and large-scale patterns of precipitation (IPCC, 2014, 2018).

This article is protected by copyright. All rights reserved. 
Importantly, the magnitude of projected changes is markedly affected by the choice of climate scenario, particularly by mid- $21^{\text {st }}$ century (IPCC, 2014). In agreement with a trend also reported by Sokolov et al (2009), the worst-case scenario (HE 8.5) considered here forecast changes in $\mathrm{T}_{\max }$ of up to $7^{\circ} \mathrm{C}$ across primate ranges. The best-case scenario, however, also predicted extreme changes in $\mathrm{T}_{\max }$ up to $5^{\circ} \mathrm{C}$ (Fig. S3). Whereas uncertainties persist regarding the magnitude of changes primates will be exposed to in the future, conservationists should not ignore the likely profound effects of this global driver on primates and their habitats, and it is vital that upstream planning take climate change effects into account to minimize future losses of primate species. Our study focused on two key components of climate change-related risks, exposure and hazard, and future work should consider how differences in species' life-history traits and behavioural flexibility affect their intrinsic vulnerability (Lehmann et al., 2010; Pacifici et al., 2018).

Finally, the choice of the spatial resolution considered ( 4.5 km grid) may explain the differences in results observed for future scenarios. Randin et al (2009) compared the effects of climate change on projected habitat loss at coarse (i.e. European scale, 10x10' grid cells) and local (25mx25m grid cells) scales, and found that all suitable habitats disappeared when forecasting at the coarse scale, whereas most of the suitable habitats persisted at the finer scale. It would be important to consider finer scales in future assessments of the effects of LUC change on primates. This will, however, require future scenarios for global LUC, which incorporate more habitat types than are presently available.

\section{Acknowledgments}

We would like to thank Tiago Marques and Kate Howie for statistical advice, and Jemma Window for help with the IUCN GIS layers. We are grateful to two anonymous reviewers for constructive comments on an earlier version of the manuscript. JSC was funded by a

This article is protected by copyright. All rights reserved. 
University of Stirling Research Programme fellowship. BG is supported by the University of Stirling's 'Contextual learning and processing in humans and machines' Research Programme.

\section{REFERENCES}

Baker, D. J., Hartley, A. J., Burgess, N. D., Butchart, S. H. M., Carr, J. A., Smith, R. J., ... Willis, S. G. (2015). Assessing climate change impacts for vertebrate fauna across the West African protected area network using regionally appropriate climate projections. Diversity and Distributions, 21(9), 991-1003.

Bello, C., Galetti, M., Pizo, M. A., Magnago, L. F. S., Rocha, M. F., Lima, R. A. F., ... Jordano, P. (2015). Defaunation affects carbon storage in tropical forests. Science Advances, 1(11), e1501105-e1501105.

Brown, J. L., \& Yoder, A. D. (2015). Shifting ranges and conservation challenges for lemurs in the face of climate change. Ecology and Evolution, 5(6), 1131-1142.

Broxton, P. D., Zeng, X., Sulla-Menashe, D., Troch, P. A., Broxton, P. D., Zeng, X., ... Troch, P. A. (2014). A global land cover climatology using MODIS data. Journal of Applied Meteorology and Climatology, 53(6), 1593-1605.

Calcagno, V. (2013). glmulti: Model selection and multimodel inference made easy. $R$ package version 1.0.7. https://CRAN.R-project.org/package=glmulti.

Calcagno, V., \& de Mazancourt, C. (2010). glmulti: An R package for easy automated model selection with (generalized) linear models. Journal of Statistical Software, 34(12), 29.

Casajus, N., Périé, C., Logan, T., Lambert, M., De, S., \& Berteaux, D. (2016). An objective approach to select climate scenarios when projecting species distribution under climate change. PLoS ONE, 1-17.

CBD (2010). The strategic plan for biodiversity 2011-2020 and the Aichi biodiversity

This article is protected by copyright. All rights reserved. 
targets. Nagoya, Japan, 18 to 29 October 2010.

Chapman, C. A., Chapman, L. J., Struhsaker, T. T., Zanne, A. E., Clark, C. J., \& Poulsen, J.

R. (2005). A long-term evaluation of fruiting phenology: Importance of climate change. Journal of Tropical Ecology, 21(01), 31-45.

Chini, L. P., Hurtt, G. C., \& Frolking, S. (2014). Harmonized global land use for years 15002100, V1. Data set. Available on-line [http://daac.ornl.gov] from Oak Ridge National ESRI (2011). ArcGIS Desktop: Release 10. Redlands, CA, USA: Environmental Systems Research Institute.

Estrada, A., Garber, P. A., Mittermeier, R. A., Wich, S., Gouveia, S., Dobrovolski, R., ... Setiawan, A. (2018). Primates in peril: The significance of Brazil, Madagascar, Indonesia and the Democratic Republic of the Congo for global primate conservation. PeerJ, 6, e4869.

Estrada, A., Garber, P. A., Rylands, A. B., Roos, C., Fernandez-Duque, E., Di Fiore, A., ... Li, B. (2017). Impending extinction crisis of the world's primates: Why primates matter. Science Advances, 3(1), e1600946.

Estrada, A., Raboy, B. E., \& Oliveira, L. C. (2012). Agroecosystems and primate conservation in the tropics: A review. American Journal of Primatology, 74(8), 696711.

Fuchs, A. J., Gilbert, C. C., \& Kamilar, J. M. (2018). Ecological niche modeling of the genus Papio. American Journal of Physical Anthropology, 166(4), 812-823.

Gaffney, L. R. (2011). Risks to global primate diversity from climate change and other pressures. Durham Thesis. Durham University.

Garden, J., O’Donnell, T., \& Catterall, C. (2015). Changing habitat areas and static reserves: Challenges to species protection under climate change. Landscape Ecology, 30(10), 1959-1973.

This article is protected by copyright. All rights reserved. 
Gouveia, S. F., Souza-Alves, J. P., Rattis, L., Dobrovolski, R., Jerusalinsky, L., BeltrãoMendes, R., \& Ferrari, S. F. (2016). Climate and land use changes will degrade the configuration of the landscape for titi monkeys in eastern Brazil. Global Change Biology, 22(6), 2003-2012.

Graham, T. L., Matthews, H. D., \& Turner, S. E. (2016). A global-scale evaluation of primate exposure and vulnerability to climate change. International Journal of Primatology, $37(2), 158-174$.

Hijmans, R. J., Cameron, S. E., Parra, J. L., Jones, P. G., \& Jarvis, A. (2005). Very high resolution interpolated climate surfaces for global land areas. International Journal of Climatology, 25(15), 1965-1978.

Hurtt, G. C., Chini, L. P., Frolking, S., Betts, R. A., Feddema, J., Fischer, G., ... Wang, Y. P. (2011). Harmonization of land-use scenarios for the period 1500-2100: 600 years of global gridded annual land-use transitions, wood harvest, and resulting secondary lands. Climatic Change, 109(1-2), 117-161.

IPCC (2014). Climate change 2014: Synthesis report. Contribution of working groups I, II, and III to the fifth assessment report of the Intergovenmental Panel on Climate Change. Geneva, Switzerland.

IPCC (2018). Global warming of $1.5^{\circ} \mathrm{C}$ - Summary for policymakers. Geneva, Switzerland. Isabirye-Basuta, G. M., \& Lwanga, J. S. (2008). Primate populations and their interactions with changing habitats. International Journal of Primatology, 29, 35-48.

IUCN (2012). IUCN guidelines for reintroductions and other conservation translocations. Gland, Switzerland.

IUCN (2018). IUCN Red List of threatened species. Version 2018.1. Available: http://www.iucnredlist.org. Downloaded on 16 March 2018.

Jablonski, N. G., Whitfort, M. J., Roberts-Smith, N., \& Qinqi, X. (2000). The influence of

This article is protected by copyright. All rights reserved. 
life history and diet on the distribution of catarrhine primates during the Pleistocene in eastern Asia. Journal of Human Evolution, 39(2), 131-157.

Jones, K. R., Venter, O., Fuller, R. A., Allan, J. R., Maxwell, S. L., Negret, P. J., \& Watson, J. E. M. (2018). One-third of global protected land is under intense human pressure. Science, 360(6390), 788-791.

Kamilar, J. M. (2017). Biogeography and primate biogeography. In The international encyclopedia of primatology (pp. 1-4). Hoboken, NJ, USA: John Wiley \& Sons, Inc.

Kamilar, J. M., \& Ledogar, J. A. (2011). Species co-occurrence patterns and dietary resource competition in primates. American Journal of Physical Anthropology, 144(1), 131-139.

Korstjens, A. H., \& Hillyer, A. P. (2016). Primates and climate change: A review of current knowledge. In S. A. Wich \& A. J. Marshall (Eds.), An introduction to primate conservation (p. 302). Oxford University Press.

Laurance, W. F., Sayer, J., \& Cassman, K. G. (2014). Agricultural expansion and its impacts on tropical nature. Trends in Ecology and Evolution, 29(2), 107-116.

Lecina-Diaz, J., Alvarez, A., Regos, A., Drapeau, P., Paquette, A., Messier, C., \& Retana, J. (2018). The positive carbon stocks-biodiversity relationship in forests: Co-occurrence and drivers across five subclimates. The Bulletin of the Ecological Society of America, 99(4), e01424.

Lehman, S. M., Fleagle, J. G., \& Tuttle, R. H. (2006). Biogeography and primates: A review. In S. M. Lehman \& J. G. Fleagle (Eds.), Primate biogeography: Progress and prospects (pp. 1-58). Chicago: University of Chicago.

Lehmann, J., Korstjens, A. H., \& Dunbar, R. I. M. (2010). Apes in a changing world - the effects of global warming on the behaviour and distribution of African apes. Journal of Biogeography, 37(12), 2217-2231.

McClean, C. J., Lovett, J. C., Küper, W., Hannah, L., Sommer, J. H., Barthlott, W., ...

This article is protected by copyright. All rights reserved. 
Taplin, J. R. D. (2005). African plant diversity and climate change. Annals of the Missouri Botanical Garden. Missouri Botanical Garden Press.

Meyer, A. L. S., Pie, M. R., \& Passos, F. C. (2014). Assessing the exposure of lion tamarins (Leontopithecus spp.) to future climate change. American Journal of Primatology, 76(6), $551-562$.

Pacifici, M., Foden, W. B., Visconti, P., Watson, J. E. M., Butchart, S. H. M., Kovacs, K. M., ... Rondinini, C. (2015). Assessing species vulnerability to climate change. Nature Climate Change, 5(3), 215-224.

Pacifici, M., Visconti, P., \& Rondinini, C. (2018). A framework for the identification of hotspots of climate change risk for mammals. Global Change Biology, 24(4), 16261636.

Peters, G. P., Marland, G., Le Quéré, C., Boden, T., Canadell, J. G., \& Raupach, M. R. (2011). Rapid growth in $\mathrm{CO}^{2}$ emissions after the 2008-2009 global financial crisis. Nature Climate Change, 2, 2-4.

Pruetz, J. D. (2018). Nocturnal behavior by a diurnal ape, the West African chimpanzee (Pan troglodytes verus), in a savanna environment at Fongoli, Senegal. American Journal of Physical Anthropology, 166(3), 541-548.

R Development Core Team. (2018). R: A language and environment for statistical computing. R Foundation for Statistical Computing, Vienna, Austria. ISBN 3-90005107-0, URL http://www.R-project.org/.

Randin, C. F., Engler, R., Normand, S., Zappa, M., Zimmermann, N. E., Pearman, P. B., ... Guisan, A. (2009). Climate change and plant distribution: Local models predict highelevation persistence. Global Change Biology, 15(6), 1557-1569.

Ribeiro, B. R., Sales, L. P., De Marco, P., \& Loyola, R. (2016). Assessing mammal exposure to climate change in the Brazilian Amazon. PLOS ONE, 11(11), e0165073.

This article is protected by copyright. All rights reserved. 
Rocha, J. M. de A., Pinto, M. P., Boubli, J. P., \& Grelle, C. E. V. (2015). The role of competition in structuring primate communities under different productivity regimes in the Amazon. PLOS ONE, 10(12), e0145699.

Root, T. L., Price, J. T., Hall, K. R., Schneider, S. H., Rosenzweig, C., \& Pounds, J. A. (2003). Fingerprints of global warming on wild animals and plants. Nature, 421(6918), $57-60$.

Schloss, C. A., Nuñez, T. A., \& Lawler, J. J. (2012). Dispersal will limit ability of mammals to track climate change in the Western Hemisphere. Proceedings of the National Academy of Sciences, 109(22), 8606-8611.

Sherwood, S. C., \& Huber, M. (2010). An adaptability limit to climate change due to heat stress. Proceedings of the National Academy of Sciences, 107(21), 9552-9555.

Sokolov, A. P., Stone, P. H., Forest, C. E., Prinn, R., Sarofim, M. C., Webster, M., ... Jacoby, H. D. (2009). Probabilistic forecast for twenty-first-century climate based on uncertainties in emissions (without policy) and climate parameters. Journal of Climate, 22(19), 5175-5204.

Spehar, S. N., Sheil, D., Harrison, T., Louys, J., Ancrenaz, M., Marshall, A. J., ... Meijaard, E. (2018). Orangutans venture out of the rainforest and into the Anthropocene. Science Advances, 4(6), e1701422.

Struebig, M. J., Fischer, M., Gaveau, D. L. A., Meijaard, E., Wich, S. A., Gonner, C., ... Kramer-Schadt, S. (2015). Anticipated climate and land-cover changes reveal refuge areas for Borneo's orang-utans. Global Change Biology, 21(8), 2891-2904.

Tacoli, C. (2009). Crisis or adaptation? Migration and climate change in a context of high mobility. Environment and Urbanization, 21(2), 513-525.

Tagg, N., McCarthy, M., Dieguez, P., Bocksberger, G., Willie, J., Mundry, R., ... Boesch, C. (2018). Nocturnal activity in wild chimpanzees (Pan troglodytes): Evidence for flexible 
sleeping patterns and insights into human evolution. American Journal of Physical Anthropology, 166(3), 510-529.

Tewksbury, J. J., Huey, R. B., \& Deutsch, C. A. (2008). Putting the heat on tropical animals. Science, 320(5881), 1296-1297.

Thomas, C. D., Cameron, A., Green, R. E., Bakkenes, M., Beaumont, L. J., Collingham, Y. C., ... Williams, S. E. (2004). Extinction risk from climate change. Nature, 427(6970), $145-148$.

Thuiller, W. (2004). Patterns and uncertainties of species' range shifts under climate change. Global Change Biology, 10(12), 2020-2027.

Titeux, N., Henle, K., Mihoub, J.-B., Regos, A., Geijzendorffer, I. R., Cramer, W., ... Brotons, L. (2017). Global scenarios for biodiversity need to better integrate climate and land use change. Diversity and Distributions, 23(11), 1231-1234.

Tylianakis, J. M., Didham, R. K., Bascompte, J., \& Wardle, D. A. (2008). Global change and species interactions in terrestrial ecosystems. Ecology Letters, 11(12), 1351-1363.

Wich, S. A., Garcia-Ulloa, J., Kühl, H. S., Humle, T., Lee, J. S. H., \& Koh, L. P. (2014). Will oil palm's homecoming spell doom for Africa's great apes? Current Biology, 24(14), $1659-1663$.

Wiederholt, R., \& Post, E. (2010). Tropical warming and the dynamics of endangered primates. Biology Letters, 6(2), 257-260.

This article is protected by copyright. All rights reserved. 
Table 1. Results from generalised linear models assessing the effects of region, conservation status, range extent and dominant habitat on changes in climatic and land use conditions under the best-case (CC 4.5 and MiniCam 4.5, respectively) and worst-case (HE 8.5 and MESSAGE 8.5 , respectively) scenarios. Only results for the best-fit model for each response variable are shown here. Significant effects are highlighted in bold. See Table S5 and S6 for full model selection results.

\begin{tabular}{|c|c|c|c|c|c|c|}
\hline \multirow{2}{*}{$\begin{array}{l}\text { Response } \\
\text { variable }\end{array}$} & \multirow[t]{2}{*}{ Predictors } & \multirow[t]{2}{*}{ Predictor levels } & \multicolumn{2}{|c|}{ Best-case scenario } & \multicolumn{2}{|c|}{ Worst-case scenario } \\
\hline & & & $\beta$ & SE & $\beta$ & $\mathrm{SE}$ \\
\hline Max. & & Intercept & $0.297^{* * *}$ & 0.031 & $1.045^{* * * *}$ & 0.025 \\
\hline temperature & Region & Asia & $0.084^{* *}$ & 0.030 & $-0.064^{*}$ & 0.031 \\
\hline & & Madagascar & $0.102^{* *}$ & 0.034 & 0.001 & 0.035 \\
\hline & & Neotropics & $0.502^{* * *}$ & 0.028 & $0.2659^{* * *}$ & 0.030 \\
\hline & Conservation status & DD & 0.079 & 0.046 & & \\
\hline & & EN & 0.034 & 0.026 & & \\
\hline & & $\mathrm{LC}$ & $0.116^{* * *}$ & 0.029 & & \\
\hline & & NT & 0.075 & 0.040 & & \\
\hline & & VU & 0.040 & 0.028 & & \\
\hline & Habitat & Other & 0.049 & 0.038 & -0.067 & 0.040 \\
\hline & & Savanna & $0.103^{*}$ & 0.045 & 0.066 & 0.048 \\
\hline & Range & Range size ${ }^{* *}$ & $1.8 \mathrm{e}-08^{*}$ & $8.4 \mathrm{e}-09$ & $3.8 \mathrm{e}-08^{\text {*** }}$ & $8.2 \mathrm{e}-09$ \\
\hline & Interactions & Asia x Other & 0.0200 & 0.058 & 0.041 & 0.062 \\
\hline & & Madagascar x Other & -0.038 & 0.066 & 0.045 & 0.070 \\
\hline & & Neotropics x Other & $-0.350^{* * *}$ & 0.071 & $-0.158^{*}$ & 0.075 \\
\hline & & Asia x Savanna & 0.098 & 0.105 & 0.131 & 0.112 \\
\hline & & Madagascar x Savanna & $-0.130^{*}$ & 0.057 & $-0.164^{* *}$ & 0.061 \\
\hline & & Neotropics x Savanna & $-0.453^{* * *}$ & 0.058 & -0.260 **** & 0.061 \\
\hline Min. & & Intercept & $0.472^{* * *}$ & 0.026 & $1.135^{* * * *}$ & 0.029 \\
\hline temperature & Region & Asia & $-0.260^{* * *}$ & 0.026 & $-0.247^{* * *}$ & 0.028 \\
\hline & & Madagascar & -0.216 *** & 0.029 & $-0.442^{* * *}$ & 0.032 \\
\hline & & Neotropics & 0.020 & 0.024 & $-0.114^{* * *}$ & 0.026 \\
\hline & Conservation status & DD & $0.097^{*}$ & 0.039 & $0.137^{* *}$ & 0.043 \\
\hline & & EN & $0.060^{* *}$ & 0.022 & 0.010 & 0.024 \\
\hline & & $\mathrm{LC}$ & $0.082^{* * *}$ & 0.025 & 0.038 & 0.027 \\
\hline & & NT & $0.096^{* *}$ & 0.033 & 0.033 & 0.037 \\
\hline & & VU & $0.050^{*}$ & 0.024 & $0.052^{*}$ & 0.026 \\
\hline & Habitat & Other & -0.099 ** & 0.032 & $-0.083^{*}$ & 0.035 \\
\hline & & Savanna & $-0.108^{* *}$ & 0.038 & -0.03 & 0.042 \\
\hline & Range & Range size & $2.1 \mathrm{e}-08^{* *}$ & $7.1 \mathrm{e}-09$ & $2.6 \mathrm{e}-08^{* * *}$ & $7.9 \mathrm{e}-09$ \\
\hline & Interactions & Asia $\mathrm{x}$ Other & $0.194^{* * *}$ & 0.049 & $0.122^{*}$ & 0.055 \\
\hline & & Madagascar x Other & $0.134^{*}$ & 0.056 & 0.068 & 0.062 \\
\hline & & Neotropics x Other & -0.090 & 0.0560 & -0.035 & 0.066 \\
\hline & & Asia x Savanna & $0.204^{*}$ & 0.089 & $0.311^{* *}$ & 0.099 \\
\hline & & Madagascar x Savanna & $0.210^{* * *}$ & 0.048 & 0.073 & 0.053 \\
\hline & & Neotropics x Savanna & -0.086 & 0.049 & $-\mathbf{0 . 1 7 8}{ }^{* *}$ & 0.054 \\
\hline
\end{tabular}

This article is protected by copyright. All rights reserved. 


\begin{tabular}{|c|c|c|c|c|c|c|}
\hline \multirow{12}{*}{$\begin{array}{l}\text { Prec. wettest } \\
\text { month }\end{array}$} & \multirow{4}{*}{ Region } & Intercept & $2.743^{* * *}$ & 0.125 & $2.677^{* * *}$ & 0.148 \\
\hline & & Asia & $0.386^{*}$ & 0.160 & 0.218 & 0.203 \\
\hline & & Madagascar & -0.139 & 0.178 & $-1.152^{* * *}$ & 0.286 \\
\hline & & Neotropics & $-0.938^{* * *}$ & 0.169 & -0.130 & 0.193 \\
\hline & \multirow[t]{2}{*}{ Habitat } & Other & $-0.495^{*}$ & 0.211 & -0.194 & 0.280 \\
\hline & & Savanna & $-0.534^{*}$ & 0.253 & $-0.819^{*}$ & 0.316 \\
\hline & \multirow[t]{6}{*}{ Interactions } & Asia $\mathrm{x}$ Other & 0.504 & 0.316 & $1.103^{*}$ & 0.426 \\
\hline & & Madagascar x Other & $0.954^{*}$ & 0.389 & $1.766^{* *}$ & 0.626 \\
\hline & & Neotropics x Other & $1.156^{*}$ & $0 . .450$ & 0.181 & 0.512 \\
\hline & & Asia x Savanna & $1.150^{*}$ & 0.561 & 0.982 & 0.676 \\
\hline & & Madagascar x Savanna & $0.802^{*}$ & 0.315 & $1.196 *$ & 0.573 \\
\hline & & Neotropics x Savanna & $1.018^{* *}$ & 0.345 & 0.056 & 0.433 \\
\hline \multirow[t]{17}{*}{ Cropland } & \multirow{4}{*}{ Region } & Intercept & -0.010 & 0.014 & $0.094^{* * * *}$ & 0.014 \\
\hline & & Asia & $0.144^{* * * *}$ & 0.013 & $0.065^{* * * *}$ & 0.014 \\
\hline & & Madagascar & 0.005 & 0.015 & $\mathbf{0 . 0 3 3}^{*}$ & 0.016 \\
\hline & & Neotropics & $0.026^{*}$ & 0.012 & $-0.061^{* * *}$ & 0.013 \\
\hline & \multirow[t]{5}{*}{ Conservation status } & DD & -0.027 & 0.020 & -0.017 & 0.021 \\
\hline & & $\mathrm{EN}$ & 0.008 & 0.011 & $0.032^{* *}$ & 0.012 \\
\hline & & $\mathrm{LC}$ & -0.004 & 0.012 & 0.012 & 0.013 \\
\hline & & NT & 0.029 & 0.017 & $0.060^{* *}$ & 0.018 \\
\hline & & VU & $-0.026^{*}$ & 0.012 & 0.005 & 0.013 \\
\hline & \multirow[t]{2}{*}{ Habitat } & Other & $0.080^{* * *}$ & 0.016 & $0.080^{* * * *}$ & 0.017 \\
\hline & & Savanna & $0.059^{* *}$ & 0.019 & 0.010 & 0.022 \\
\hline & \multirow[t]{6}{*}{ Interactions } & Asia $x$ Other & $0.065^{*}$ & 0.026 & 0.053 & 0.027 \\
\hline & & Madagascar x Other & $-0.085^{* *}$ & 0.028 & $-0.098^{* * *}$ & 0.029 \\
\hline & & Neotropics x Other & -0.018 & 0.031 & 0.059 & 0.033 \\
\hline & & Asia x Savanna & $0.100^{*}$ & 0.046 & 0.012 & 0.049 \\
\hline & & Madagascar x Savanna & -0.046 & 0.025 & -0.045 & 0.026 \\
\hline & & Neotropics x Savanna & 0.001 & 0.025 & $0.100^{* * *}$ & 0.027 \\
\hline \multirow{12}{*}{$\begin{array}{l}\text { Secondary } \\
\text { Land }\end{array}$} & \multirow{4}{*}{ Region } & Intercept & $0.306^{* * *}$ & 0.025 & $\mathbf{0 . 0 7 8}^{* *}$ & 0.027 \\
\hline & & Asia & $-0.086^{* *}$ & 0.332 & $0.099^{* *}$ & 0.034 \\
\hline & & Madagascar & $0.088^{*}$ & 0.035 & $-0.348^{* * *}$ & 0.039 \\
\hline & & Neotropics & $-0.075^{*}$ & 0.030 & $0.099^{* *}$ & 0.033 \\
\hline & \multirow[t]{2}{*}{ Habitat } & Other & $-0.273^{* * *}$ & 0.040 & $-0.231^{* * *}$ & 0.044 \\
\hline & & Savanna & $-0.205^{* * *}$ & 0.048 & -0.053 & 0.052 \\
\hline & \multirow[t]{6}{*}{ Interactions } & Asia $x$ Other & $0.288^{* * *}$ & 0.063 & $0.242^{* * *}$ & 0.069 \\
\hline & & Madagascar x Other & $0.195^{* *}$ & 0.068 & $0.307^{* * *}$ & 0.074 \\
\hline & & Neotropics x Other & $0.275^{* * *}$ & 0.075 & 0.075 & 0.082 \\
\hline & & Asia x Savanna & 0.189 & 0.113 & -0.025 & 0.123 \\
\hline & & Madagascar x Savanna & $0.166^{* *}$ & 0.061 & $0.295^{* * * *}$ & 0.067 \\
\hline & & Neotropics x Savanna & $0.211^{* * *}$ & 0.061 & 0.042 & 0.067 \\
\hline \multirow[t]{6}{*}{ Primary land } & \multirow{4}{*}{ Region } & Intercept & $-0.743^{* * * *}$ & 0.028 & $-0.789^{* * *}$ & 0.035 \\
\hline & & Asia & $0.330^{* * *}$ & 0.035 & $0.360^{* * * *}$ & 0.035 \\
\hline & & Madagascar & 0.043 & 0.039 & 0.033 & 0.039 \\
\hline & & Neotropics & $0.341^{* * *}$ & 0.034 & $0.348^{* * *}$ & 0.033 \\
\hline & \multirow{2}{*}{ Conservation status } & DD & & & 0.085 & 0.053 \\
\hline & & $\mathrm{EN}$ & & & -0.047 & 0.030 \\
\hline
\end{tabular}

This article is protected by copyright. All rights reserved. 


\begin{tabular}{llllll} 
& LC & & & 0.037 & 0.033 \\
NT & & & 0.025 & 0.046 \\
Habitat & VU & & 0.007 & 0.032 \\
& Other & 0.021 & 0.045 & 0.022 & 0.043 \\
Range & Savanna & 0.015 & 0.053 & -0.043 & 0.052 \\
Interactions & Range size & & -171.9 & 115.3 \\
& Asia x Other & $\mathbf{- 0 . 2 0 8}^{* *}$ & 0.070 & $\mathbf{- 0 . 2 1 4}^{* *}$ & 0.068 \\
& Madagascar x Other & 0.129 & 0.075 & 0.130 & 0.072 \\
& Neotropics x Other & $\mathbf{- 0 . 3 9 8}^{* * *}$ & 0.083 & $\mathbf{- 0 . 4 2 1}^{* * *}$ & 0.081 \\
& Asia x Savanna & $\mathbf{- 0 . 3 3 2}^{* *}$ & 0.125 & -0.108 & 0.121 \\
& Madagascar x Savanna & 0.108 & 0.068 & 0.077 & 0.066 \\
& Neotropics x Savanna & $\mathbf{- 0 . 3 1 7}^{* * *}$ & 0.068 & $\mathbf{- 0 . 3 6 1}^{* * *}$ & 0.067 \\
\hline
\end{tabular}

$\beta:$ parameter estimates; SE: standard error; ${ }^{*} \mathrm{p}<0.05,{ }^{*} \mathrm{p}<0.01,{ }^{* * *} \mathrm{p}<0.001$

This article is protected by copyright. All rights reserved. 
Table 2. List of the primate species likely to be most exposed to extreme climate change, defined here as those species which are projected to experience increases in the maximum temperature of the warmest month $\left(\mathrm{T}_{\max }\right)$ above $4^{\circ} \mathrm{C}$ in more than $50 \%$ of their range under the worst-case scenario (HE 8.5).

\begin{tabular}{|c|c|c|c|c|c|}
\hline Region/Family & Species & $\begin{array}{l}\text { Conservation } \\
\text { status }\end{array}$ & $\begin{array}{c}\text { Current } \\
\text { Range } \\
\left(\mathrm{km}^{2}\right)\end{array}$ & $\begin{array}{l}\text { Current } \\
\text { Habitat }\end{array}$ & $\begin{array}{c}\text { Exposed } \\
\text { Range } \\
(\%)\end{array}$ \\
\hline \multicolumn{6}{|l|}{ AFRICA } \\
\hline Cercopithecidae & Macaca sylvanus & EN & 95,557 & other & 76.8 \\
\hline \multicolumn{6}{|l|}{ ASIA } \\
\hline Cercopithecidae & Trachypithecus laotum & VU & 5,592 & forest & 100 \\
\hline \multirow{2}{*}{ Hylobatidae } & Nomascus siki & EN & 26,549 & forest & 67.3 \\
\hline & Nomascus leucogenys & CR & 51,338 & forest & 66.9 \\
\hline \multicolumn{6}{|l|}{ NEOTROPICS } \\
\hline \multirow[t]{2}{*}{ Aotidae } & Aotus azarae & $\mathrm{LC}$ & $3.162,698$ & forest & 75.0 \\
\hline & Aotus trivirgatus & $\mathrm{LC}$ & 752,040 & forest & 61.1 \\
\hline \multirow[t]{7}{*}{ Atelidae } & Alouatta discolor & VU & 375,736 & forest & 100 \\
\hline & Ateles marginatus & EN & 524,096 & forest & 100 \\
\hline & Alouatta belzebul & VU & 866,694 & forest & 82.1 \\
\hline & Ateles paniscus & VU & $1.061,274$ & forest & 81.8 \\
\hline & Alouatta macconnelli & $\mathrm{LC}$ & $1.763,215$ & forest & 67.8 \\
\hline & Alouatta caraya & $\mathrm{LC}$ & $3.064,124$ & savanna & 63.9 \\
\hline & Alouatta nigerrima & $\mathrm{LC}$ & 236,116 & forest & 62.5 \\
\hline \multirow{12}{*}{ Callitrichidae } & Mico emiliae & $\mathrm{DD}$ & 151,986 & forest & 100 \\
\hline & Mico humeralifer & $\mathrm{DD}$ & 63,580 & forest & 100 \\
\hline & Mico leucippe & VU & 14,839 & forest & 100 \\
\hline & Saguinus martinsi & $\mathrm{LC}$ & 42,109 & forest & 100 \\
\hline & Mico argentatus & $\mathrm{LC}$ & 137,206 & forest & 99.9 \\
\hline & Mico rondoni & VU & 70,575 & forest & 97.2 \\
\hline & Mico intermedius & $\mathrm{LC}$ & 62,624 & forest & 97.0 \\
\hline & Saguinus niger & VU & 587,634 & forest & 84.5 \\
\hline & Mico melanurus & $\mathrm{LC}$ & 850,115 & savanna & 81.9 \\
\hline & Saguinus midas & $\mathrm{LC}$ & 863,249 & forest & 76.3 \\
\hline & Callithrix penicillata & $\mathrm{LC}$ & $1.309,803$ & savanna & 74.8 \\
\hline & Mico mauesi & $\mathrm{LC}$ & 29,586 & forest & 66.7 \\
\hline \multirow[t]{6}{*}{ Cebidae } & Sapajus apella & $\mathrm{LC}$ & $3.355,096$ & forest & 75.3 \\
\hline & Sapajus libidinosus & $\mathrm{LC}$ & $2.612,534$ & savanna & 67.6 \\
\hline & Saimiri ustus & NT & 876,708 & forest & 65.9 \\
\hline & Cebus kaapori & $\mathrm{CR}$ & 190,774 & forest & 62.3 \\
\hline & Saimiri sciureus & $\mathrm{LC}$ & $4.419,721$ & forest & 55.5 \\
\hline & Sapajus cay & $\mathrm{LC}$ & 620,932 & savanna & 51.1 \\
\hline \multirow[t]{7}{*}{ Pitheciidae } & Callicebus baptista & $\mathrm{LC}$ & 14,741 & forest & 100 \\
\hline & Callicebus moloch & $\mathrm{LC}$ & 944,027 & forest & 100 \\
\hline & Chiropotes utahickae & $\mathrm{EN}$ & 352,113 & forest & 99.7 \\
\hline & Callicebus hoffmannsi & $\mathrm{LC}$ & 92,128 & forest & 96.3 \\
\hline & Chiropotes albinasus & EN & 981,532 & forest & 86.3 \\
\hline & Pithecia pithecia & $\mathrm{LC}$ & $1.105,061$ & forest & 74.7 \\
\hline & Chiropotes chiropotes & $\mathrm{LC}$ & $1.363,870$ & forest & 73.6 \\
\hline
\end{tabular}

This article is protected by copyright. All rights reserved. 


\begin{tabular}{lllcl} 
Callicebus pallescens & LC & 417,318 & forest & 73.5 \\
Chiropotes satanas & CR & 273,122 & savanna & 72.4 \\
Callicebus cinerascens & LC & 210,384 & forest & 69.0 \\
Callicebus brunneus & LC & 243,776 & forest & 67.6 \\
\hline
\end{tabular}

${ }^{*}$ CR: Critically Endangered, EN: Endangered, VU: Vulnerable, NT: Near Threatened, LC: Least Concern, DD: Data Deficient

This article is protected by copyright. All rights reserved. 
Figure 1. Projected changes in climatic conditions across primate ranges for 2050. Results are only shown for the best-case scenario and worst-case scenario chosen to represent each climatic variable in the future: CC 4.5 (i.e. CCSM4 RCP 4.5) and HE 8.5 (i.e. HadGEM-ES RCP 8.5), respectively.

Figure 2. Projected changes in land use/cover (LUC) conditions across primate ranges for 2050. For each LUC variable, the results are shown for the best-case scenario (MiniCam 4.5) and worst-case scenario (MESSAGE 8.5).

Figure 3. Cumulative percentage of range (total and by family) within each region likely to be exposed to different magnitudes of change in the maximum temperature of the warmest month $\left({ }^{\circ} \mathrm{C}\right)$ under the worst-case scenario (HE 8.5) for 2050.

Figure 4. Percentage of primate range (by region) likely to be exposed to different magnitudes of changes in the maximum temperature of the warmest month $\left({ }^{\circ} \mathrm{C}\right)$ under the worst-case scenario (HE 8.5) for 2050 across the different classes of primate species diversity (1-5, 6-10, 11-15, and 16-19 sympatric species).

This article is protected by copyright. All rights reserved. 
(a) Best-case scenario
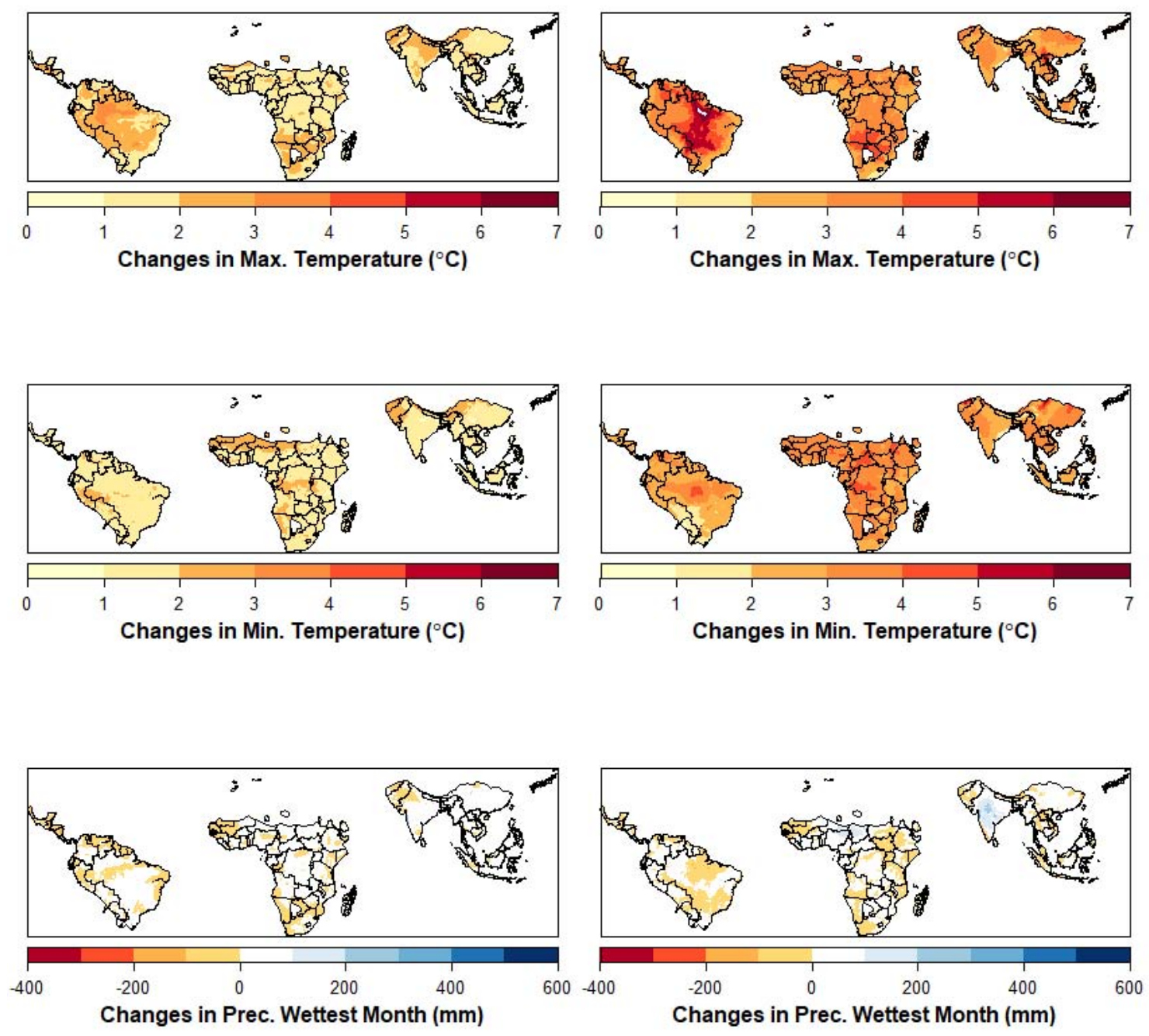

This article is protected by copyright. All rights reserved. 
(a) Best-case scenario
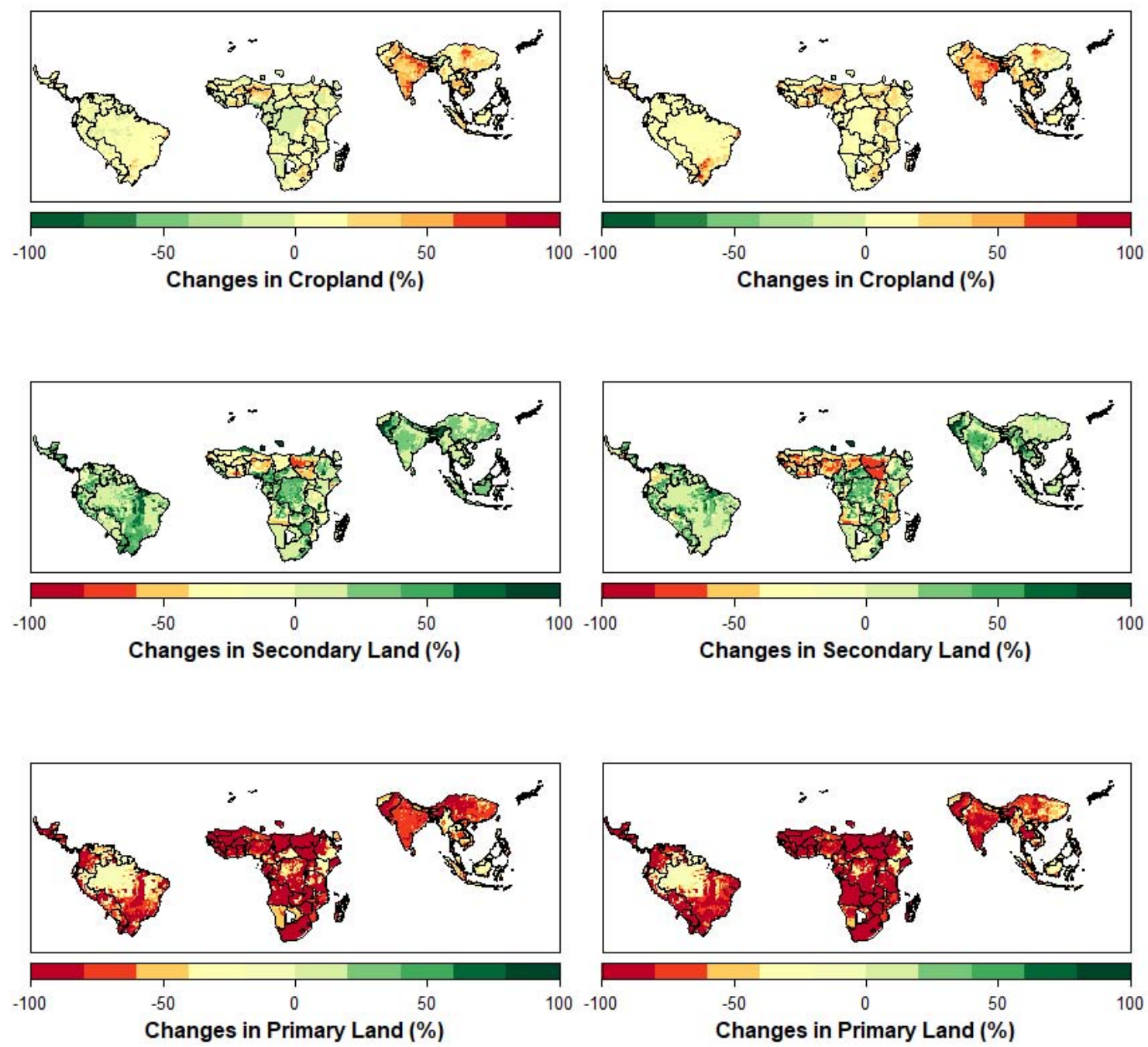

This article is protected by copyright. All rights reserved. 
Changes in Max. Temperature $\left({ }^{\circ} \mathrm{C}\right)$

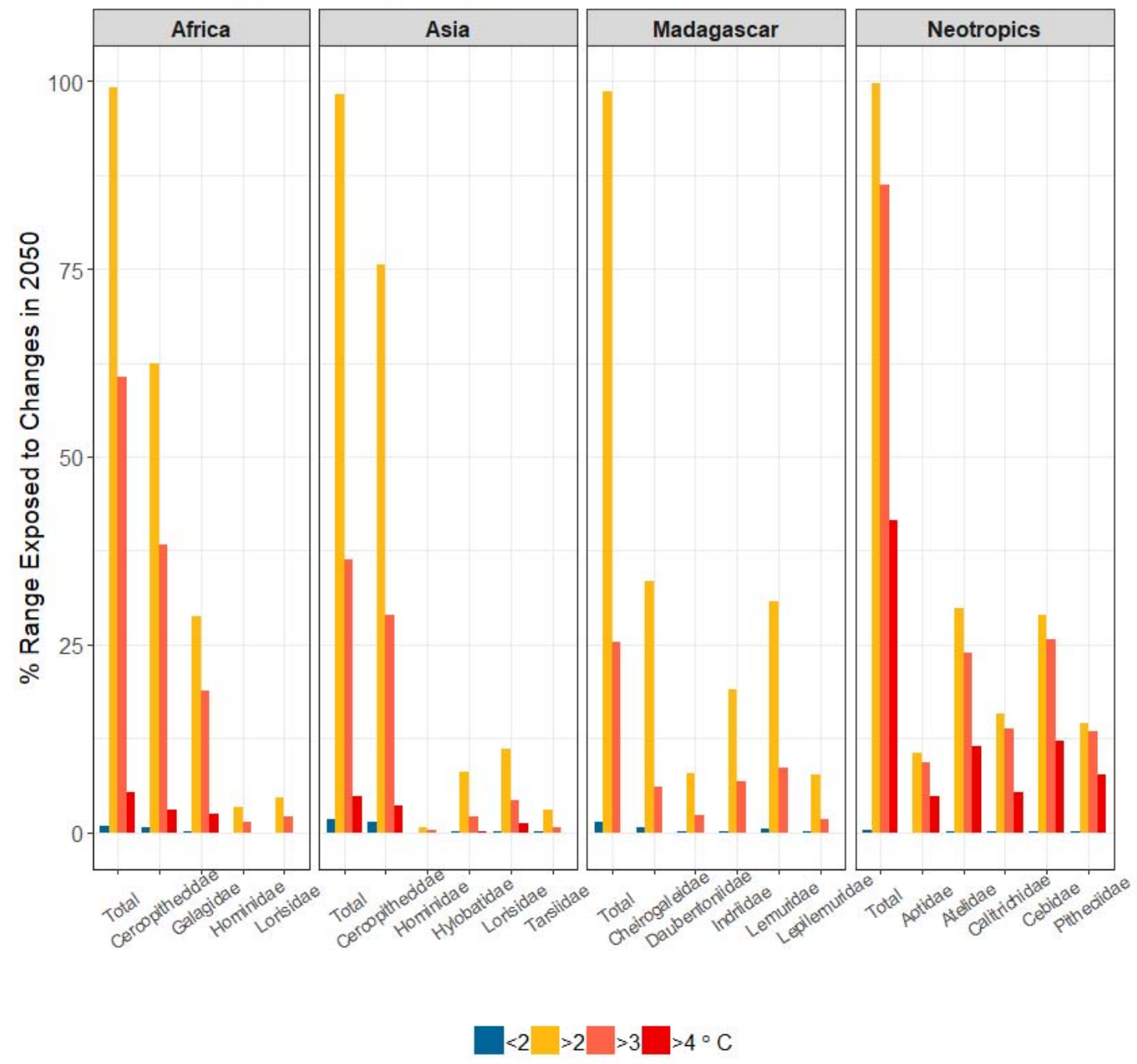

This article is protected by copyright. All rights reserved. 
Changes in Max. Temperature $\left({ }^{\circ} \mathrm{C}\right)$

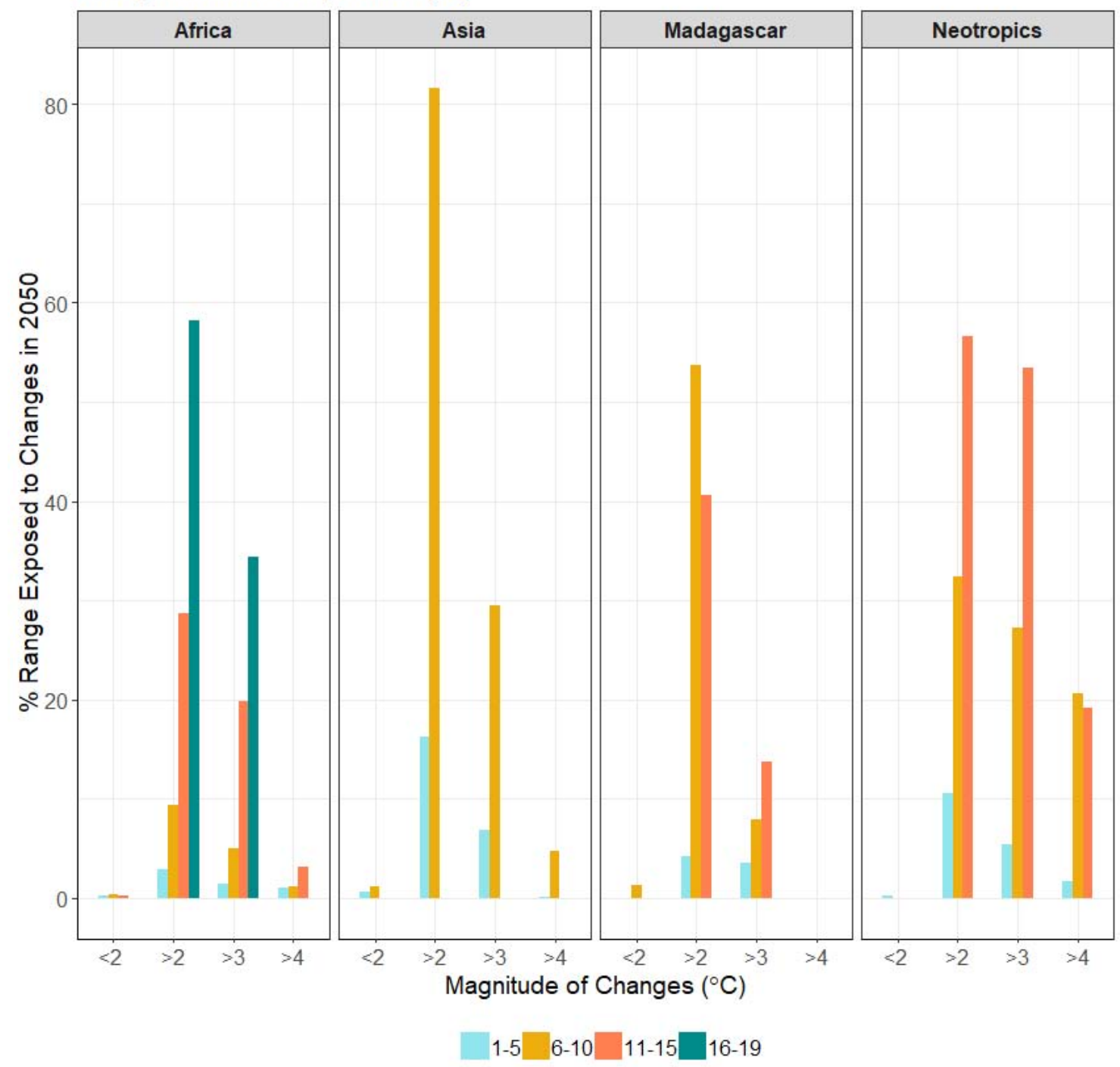

This article is protected by copyright. All rights reserved. 